\title{
Analysis of Number of Players Involved in Rebound Situations in Euroleague Basketball Games
}

\author{
Roberto Lampert Ribas ${ }^{1, *}$ Rafael Navarro ${ }^{2}$, Fernando Tavares ${ }^{1}$ and Miguel Ángel Gómez ${ }^{3}$ \\ ${ }^{I}$ Faculty of Sports Sciences and Physical Education, University of Porto, Portugal \\ ${ }^{2}$ Faculty of Physical Activity and Sport Sciences, University Alfonso X El Sabio \\ ${ }^{3}$ Faculty of Physical Activity and Sport Sciences, Polytechnic University of Madrid, Spain
}

\begin{abstract}
The aim of the present study was to identify the influence of number of players involved in dispute of rebound in basketball games.To do so, 48 games corresponding to the 2009-2010 Top 16 of the Euroleague were analyzed.The sample was composed of 2170 situations (unsuccessful field-goals gathered which generate rebound), and the analyzed variables were: i)situations of equal number of 1,2 and 3 players from offense and defense in rebound; ii) situations of superiority of 1, 2 and 3 players for defense; iii) situations of superiority of 1 player for offense; iv) all situations of superiority and inferiority in offense and defensive rebounds. The results of the present study showed that: i) when the number of players is equal, defense had no statistically significant more rebounds than offense; ii) when defense had superiority of 1, 2 and 3 players, it had statistically significant more rebounds than offense; iii) when offense had superiority of 1 player, it had statistically significant more rebounds than defense; iv) situations of superiority had statistically significant more rebounds than inferiority. Coaches and researches should be aware of this kind of information to enhance practices and games performance.
\end{abstract}

Keywords: Basketball, field-goal attempt,notational analysis, rebound, superiority.

\section{INTRODUCTION}

The investigation of factors which influence the performance in high level basketball games is relevant to affect the evolution of a sport. The detailed information about players and teams is an important tool for coaches to build the training process with more validity and success. This allows relating the performance of teams with technical and tactical indicators used during the game and thusdevelop a better improvement of training programs [1].The information obtained through the analysis of the game in different situations allows identifying the tendencies of evolution of the players game and helps to optimize the preparation process [2].

Currently, there are two aspects clearly different that address the scientific knowledge in sports [3], biomechanics and notational analysis. Both perspectives are related using the technology of images to obtain information and deepen the analysis. Thus, coaches and sport-analysts can use data to compare the results between teams and players. In the case of notational analysis, the mainly indicators used are: i) from games, ii) tactical and iii) technical; which allow to know physiological, psychological, technical and tactical demands of each sport. These indicators are related to quality of performance, with the main purpose of obtaining useful information and adjustingtrainings and tasks to the reality of players or teams analyzed.Particularly, in the case of basketball, some authors [1] established that performance analysis

*Address correspondence to this author at the Faculty of Sports Sciences and Physical Education, University of Porto, Portugal; Tel: (55)51-93916294; E-mail: robertobreak@hotmail.com has focused its attention on players and the evaluation of the game, attempting to know better the aspects that allowto optimize the resources of players and teams, and also identify the competition demands. However, to ensure relevant and objective information, the purposes of observation should be clearly defined. It is necessary to determine how you intend to do the observation during the game and how the results collected can be used to improve the training process.

With the evolution of the game, researchers [4] observedthe need to introduce scientifically-based, sportspecific training, demands integration of the high expert and scientific approach to rational modeling of the training process in order to create effective system that would produce top basketball players and, as an expected consequence, top competitive results as well.

The research about game indicators in basketball has reached great importance, but mainly focused on differentiating winning and losing teams $[5,6]$. In this topic, there are some studies [6-8] that showed the importance of some variables in basketball. One of those variables is the rebound (offensive and defensive). In particular, one research [6] showed that the variables that better differentiate winners from losers in a global way were defensive rebounds and assists. However, with a lot of studies about what is really important in basketball, it is difficult to find researches where the rebound is studied, for example, where the ball tends to rebound or the difference about number of players involved in the dispute of rebounds. One research [9] about rebound possession zone showed that players need to know that shots taken from some ranges will rebound closer to the 
basket than shots launched from other distances, but this study does not report the difference about the number of players involved in the dispute of rebound.

If the contribution of rebounds to winning high level basketball games is so important, we ask ourselves why it is so difficult to find researches where this variable is studied more deeply. Thereby, we think it is important to all coach staff to know if there is any difference of chance to gain rebounds with more, same or less players involved in the dispute of rebounds. Thus, the present study aims to analyze the influence of the number of players involved in rebounds in basketball games.

\section{METHODS}

\section{Sample and Variables}

In order to carry out this study, all games $(n=48)$ corresponding to the 2009-2010 Top 16 of the Euroleague were analyzed. The games were analyzed through systematic observation by two experienced observers trained for this observational analysis.Before the analysis of the games two separate observations were done to calculate interrater reliability. From a sub-sample of 10 games, all variables were analyzed, the maximum Cohen' Kappa was 0.97 for equality 1 player and the minimum was 0.86 for superiority 3 players defense.

The variables were determined by expert coaches and researchers and were registered by experienced observers (licensed in Sport Science and with a minimum of 5 years of experience as basketball coaches). A total of 2170 actions of unsuccessful attempted field goals, which generate rebounds were analyzed. To avoid inconsistencies with the sample some actions were excluded from analysis (blocked shots, free throws attempted that did not touch the rim or the backboard, shooting foul, when the rebound went directly to out of bounds, second attempted field goal and held ball in the rebound). After an unsuccessful attempt, the number of defensive and offensive players in the dispute of rebound were analyzed. To be considered in a dispute, the player must make some action in order to gain advantage to try to gain the rebound. The rebound situations analyzed were: i) 1 player from offense and defense; ii) 2 players from offense and defense; iii) 3 players from offense and defense; iv) advantage of 1 player to defense; v) advantage of 2 players to defense; vi) advantage of 3 players to defense;vii) advantage of 1 player to offense and viii)all situations of superiority and inferiority in offense and defensive rebounds. The other situations were not analyzed due to the lower number of actions (ex: advantage of 4 or 5 players to defense, advantage of 2, 3, 4 and 5 players to offense and $4 \times 4$ and $5 \times 5$ ).

\section{Data Analysis}

A normality test (Shapiro-Wilk) was performed in all variables and afterwards a t-test for independent samples was used to examine if there were differences between the number of rebounds obtained from defense and offense in all situations. All variables were considered normal. The statistical analyses were performed using SPSS software 16.0 and significance level was set at $p \leq 0.05$.

\section{RESULTS}

The results in Table $\mathbf{1}$ showed that the defense had no statistically significant more rebounds than offense when the number of players involved in the dispute is equal. When the number of players involved is different, defense and offense had statistically significant more rebounds when they had an advantage in the number of players involved. It was also found that defensive and offensive situations with superiority had statistically significant more rebounds than inferiority situations.

\section{DISCUSSION}

The intention of the present study was to analyze different situations in rebound and if there was any difference between defense and offense when the number of players involved in the dispute of the rebound is equal, with superiority of 1 player to offense and with superiority of 1,2 and 3 players to defense.

The rebound is a very important part of basketball games, but it is not easy to find researches about what players

Table 1. Analysis of Situations in Rebounds

\begin{tabular}{|c|c|c|c|c|c|c|}
\hline & \multicolumn{2}{|c|}{ Defense } & \multicolumn{2}{|c|}{ Offense } & \multirow[t]{2}{*}{$t$} & \multirow[t]{2}{*}{ Sig. } \\
\hline & Mean & $S D$ & Mean & $S D$ & & \\
\hline Equality 1 Player & 2,45 & 1,72 & 2,31 & 1,5 & 0,441 & 0,660 \\
\hline Equality 2 Players & 3,06 & 1,87 & 2,45 & 1,42 & 1,777 & 0,079 \\
\hline Equality 3 Players & 1,35 & 1,49 & 1,5 & 1,27 & $-0,515$ & 0,608 \\
\hline Superiority 1 Player Defense & 15,68 & 4,67 & 4,2 & 2,37 & 15,156 & $0,000^{*}$ \\
\hline Superiority 2 Players Defense & 7,66 & 3,49 & 0,75 & 0,78 & 13,393 & $0,000^{*}$ \\
\hline Superiority 3 Players Defense & 1,6 & 1,51 & 0,2 & 0,14 & 7,221 & $0,000 *$ \\
\hline \multirow[t]{3}{*}{ Superiority 1 Player Offense } & 0,2 & 0,58 & 1,37 & 1,16 & $-6,228$ & $0,000 *$ \\
\hline & \multicolumn{2}{|c|}{ Inferiority } & \multicolumn{2}{|c|}{ Superiority } & \multirow[t]{2}{*}{$t$} & \multirow[t]{2}{*}{ Sig. } \\
\hline & Mean & $S D$ & Mean & $S D$ & & \\
\hline All Situations & 5,31 & 2,63 & 26,27 & 6,54 & $-20,588$ & $0,000 *$ \\
\hline
\end{tabular}

Significantly different: ${ }^{*} p \leq 0.05$. 
should do to gain rebounds in game situation, for example, how they should be positioned and fight for the rebound. The coach staff also do not have a large number of references to study, of course it is possible to find some books from more experienced coaches [10,11], but scientific publications about this variable are needed for a better performance in the game.

It was found in this study that when the number of players involved (1,2 and 3 ) in the dispute of the rebound is equal, there is no advantage to defense or offence. This allows us to think that with equality, players must fight to obtain a better position to try to win the dispute. Researchers [12] enumerates some important aspects for the players to perform well in rebound, and some of those are technical and tactical preparation, pivoting, blocking, anticipation, securing and pulling the ball away. If the free space is the same for the players to dispute position, it seems very important for them to anticipate the opponent. The best way to try to think before the opponent is practicing anticipation and decision making tasks. The players who usually go to fight for the rebound, should know exactly where the ball tends to rebound according to the player who is shooting the ball (e.g, specific position, player experience, defensive pressure, etc), if they control thesefactors better they may anticipate the move and try a better position to gain the rebound [9].

According to authors [13], performance analysis in basketball is a fundamental tool for coaches, allowing them to have valid and reliable information concerning their team and opponents. This assumption shows that the results found in the present study can help coaches, because all the situations that had advantage on the number of players involved in the rebound, won statistically significant more rebounds. When defense has advantage of 1, 2 or 3 players, in all of those situations, defense won statistically significant more rebounds than offense. This also happened when offense had advantage of 1 player in the dispute. Another situation that was analyzed was superiority and inferiority,while superiority wins near 26 rebounds per game, inferiority win less than 6 rebounds. With those numbers, superiority wins statistically significant more rebounds than inferiority.

Coaches must know in depth their opponents, for example, if the coach staff knows exactly how many players the other team uses to dispute the rebound, they can prepare their teams to have always a higher number of players disputing the ball, according to the results found in the present study, the team which is well prepared to a situation like this, will win significant more rebounds than its opponent.

The results obtained in situations with advantage for offense or defense showed that it is very difficult to gain rebounds with fewer players. If defense has inferioritythe offense canwin rebounds because at least one player is completely free to go after the rebound, the opposite situation is also true, the defense with more players can box out the players from offense and the others go to get the rebound. If the defense is playing a zone situation with inferiority, players from offense should move more quickly to confuse the defense and have a better position to jump and try to get the board, and in superiority the defense can put each player in one specific zone to box out the players in that zone and not allow the opponent to jump after the ball.

One intriguing result obtained was the number of rebounds gained when superiority occurs. When the team has more players in rebound the number of rebounds gained is bigger. Teams should be prepared to always have more players in the dispute of the rebound. The rebound must be disputed with all players, not just centers.As some authors argued, power forwards, forwards and guards can contribute to obtain the rebounds [14], and then team would have superiority and may win more boards.

The present research had some limitations that were not controlled. It was not verified the exact positions of the players when they were in the dispute of the rebound. It is interesting in further research to control this kind of information to have a better perspective of this important variable.

\section{CONCLUSION}

The analysis of number of players involved in rebound situations allowed us to understand that it is very important have superiority in the dispute. This profile can help coaches to prepare specific practices according to their opponents, this way they can perform better in the games.

\section{ACKNOWLEDGEMENT}

None declared.

\section{CONFLICTS OF INTEREST}

\author{
None declared.
}

\section{REFERENCES}

[1] Barris S, Button C. A Review of Vision-Based Motion Analysis in Sport.Sports Med 2002; 38: 1025-43.

[2] Hughes M, Franks I. Notational analysis of sport. Systems for better coaching and performance in sport, London: Routledge 2004.

[3] Hughes M, Bartlett R. The use of performance indicators in performance analysis. J Sports Sci 2002; 20: 739-54.

[4] Trninic S, Dizdar D, Luksic E. Differences between winning and defeated top quality basketball teams in final tournaments of European club championship. CollAntropol 2002; 26: 521-31.

[5] Csataljay G, O'Donoghue P, Hughes M, Dancs H. Performance indicators that distinguish winning and losing teams in basketball.Int J Perform Anal Sport 2009; 9: 60-6.

[6] Gómez MA, Lorenzo A, Sampaio J, Ibáñez S, Ortega E. Game related statistics that discriminated winning and losing teams from Spanish men's professional basketball teams. Coll Antropol 2008; 32: 451-6.

[7] Ibáñez SJ, Sampaio AJ, Sáenz-López P, Giménez J, Janeira MA. Game statistics discriminating the final outcome of Junior World Basketball Championship matches (Portugal 1999). J Hum Movement Stud 2003; 45: 1-19.

[8] Karapidis A, Fotinakis P, Taxildaris K,Fatouros J. Factors characterizing a successful performance in basketball. J Hum Movement Stud 2001; 41: 385-97.

[9] Tsamourtzis E, Athanasiou N. Registration of rebound possession zones in basketball. Int J Perform Anal Sport 2004; 4(1): 34-9.

[10] Oliver D. Basketball on paper. Rules and Tools for Performance Analysis, Washington, D. C.: Brassey's, Inc. 2004.

[11] Wootten M. Coaching basketball successfully, Champaign: Hum Kinet 2003.

[12] Sampaio J, Janeira M. Statistical analyses of basketball team performance: understanding teams' wins and losses according to a different index of ball possessions. Int J PerformAnal Sport 2003; 1: $40-9$. 
[13] Ibáñez S, García J, Feu S, Lorenzo A, Sampaio J. Effects of consecutive basketball games on the game-related statistics that discriminate winner and losing teams. J Sports Sci Med 2009; 8: $458-62$.
[14] Sampaio J, Ibañez S, Lorenzo A, Gómez MA. Discriminative game-related statistics between basketball starters and non-starters when related to playing standard and game outcome. Percept Mot Skills 2006; 103: 486-94.

Received: May 19, 2011

(C) Ribas et al.; Licensee Bentham Open.

This is an open access article licensed under the terms of the Creative Commons Attribution Non-Commercial License (http://creativecommons.org/licenses/ by-nc/3.0/) which permits unrestricted, non-commercial use, distribution and reproduction in any medium, provided the work is properly cited. 